\title{
Relationships between milk fat and rumination time recorded by commercial rumination sensing systems
}

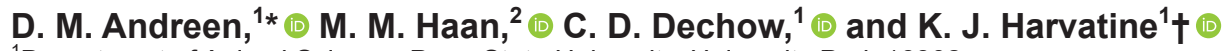 \\ ${ }^{1}$ Department of Animal Science, Penn State University, University Park 16802 \\ ${ }^{2}$ Penn State Extension, Leesport, PA 19533
}

\begin{abstract}
Low rumination in the dairy cow is often assumed to result in reduction of saliva flow, rumen buffering, and milk fat, which is a major contributor to milk value in many pricing systems. Rumination time (RT) of individual cows can be measured with commercial rumination sensing systems, but our understanding of how daily RT (minutes per day) is related to milk fat production is limited. Our hypothesis was that between cows within a herd, greater RT would be associated with lower milk fat concentration. Data from 1,823 cows on 2 commercial dairy farms in Pennsylvania over 8 DHIA tests were analyzed for a total of 8,587 cow testdays. Rumination was measured on farm A with CowManager SensoOr ear tags (Agis Automatisering BV, Harmelen, the Netherlands) and on farm B with SCR Hi-Tag neck collars (SCR Engineers, Netanya, Israel). Rumination data were collected for 7 consecutive days leading up to each DHIA test, summed within day, and averaged across days. Data were analyzed using linear mixed models with a repeated effect of test day. Daily RT reported by commercial rumination systems varied across and within cows and was strongly influenced by a cow effect. Greater RT tended to be associated with a small decrease in milk fat concentration in farm $\mathrm{A}$, but was not related to milk fat in farm B. The reason for this difference is unclear, but may be related to a potentially greater prevalence of biohydrogenation-induced milk fat depression on farm A. The significant, but small, model coefficients for milk fat and RT indicate that the relationship between these variables may not be strong enough to permit identification of cows with biohydrogenation-induced milk fat depression based on
\end{abstract}

Received November 12, 2019.

Accepted April 8, 2020.

*Current address: USDA Agricultural Research Service Pasture Systems and Watershed Management Research Unit, University Park, PA.

†Corresponding author: kjh182@psu.edu
RT from commercial systems alone. Research assessing changes in rumination before, during, and after onset of altered rumen fermentation is necessary to determine whether RT could be used to identify cows with altered rumen fermentation.

Key words: rumination, milk fat depression, milk fat, dairy cows

\section{INTRODUCTION}

Fat is the most variable component of milk; it is influenced by many interacting factors including genetics, management, and nutrition. Increased rumination has long been associated with increased milk fat concentration, with the general dogma that insufficient rumination leads to low rumen $\mathrm{pH}$ and reduced milk fat concentration (Allen, 1997). However, daily rumination time (RT) varies greatly between individual cows, and associations between rumination and milk fat concentration in commercial dairy herds have not been well investigated (Beauchemin, 2018). Modern rumination sensing systems can record rumination of individual cows continuously, but our understanding of how to use these data in nutritional management to increase milk fat is currently limited.

Interestingly, recent research has indicated that rumination may not be linearly or positively associated with milk fat, contrary to previous expectations; Johnston and DeVries (2018) observed a quadratic relationship between RT and milk fat concentration, with the relationship becoming negative beyond $\sim 450 \mathrm{~min} / \mathrm{d}$ of rumination. In a previous, unpublished, study in our laboratory that included single test-day data from 1,733 cows on 5 farms, no relationship was observed between baseline daily RT and milk fat production. However, the experiment observed only a single test day, limiting the opportunity to model cow effects on rumination and milk fat. The objectives of this experiment were to characterize variation in rumination within and between cows over time, and to examine the relationships between rumination and milk fat over multiple test days. The hypothesis was that greater rumination 
time would be associated with lower milk fat concentration in individual cows, and that individual cow effects would be a major contributor to variation in RT.

\section{MATERIALS AND METHODS}

\section{Farms and Data Collection}

Data were collected from 2 commercial dairy farms with different rumination sensing systems. Both farms were included in a previous experiment and were selected based on similar herd size, ease of data collection, and differing average milk fat production (high vs. moderate). Farm A had CowManager SensoOr ear tags (CM; Agis Automatisering BV, Harmelen, the Netherlands) on all lactating cows and farm B had SCR Hi-Tag neck collars (SCR; model HR-LDn, SCR Engineers, Netanya, Israel) on all lactating cows. The CM system has been previously validated by Bikker et al. (2014) and Borchers et al. (2016), and the SCR system was validated by Schirmann et al. (2009) and Ambriz-Vilchis et al. (2015). Both farms were located in Pennsylvania and housed 600 to 700 lactating Holstein cows in freestalls. Each farm milked 3 times per d, and fed cows a corn silage-based TMR. Data from cows that were less than 30 DIM on the test day were excluded to avoid effects of transition period metabolic conditions that may influence RT and milk fat concentration. Test-day milk production, RT (minutes per day), and cow information from a total of 1,823 cows $(1,055$ cows from farm $\mathrm{A}$ and 768 from farm B) were collected over 8 DHIA test days for each farm between January 2018 and January 2019 (8,586 cow test-days total). Cow information (DIM, parity, breed, genetic information) and DHIA test data (milk fat, protein, and SCC content) were downloaded from herd management software (PCDART; Dairy Records Management Service, Raleigh, NC). Herds were tested at one milking on each test day, and composition standardized for $\mathrm{AM} / \mathrm{PM}$ and milking interval based on respective DHIA methods. Milk samples from each test were analyzed for fat and protein content via Fouriertransformed mid infrared spectrum, and for SCC via flow cytometry, at Dairy One DHIA (Ithaca, NY) for farm A, and Lancaster DHIA (Manheim, PA) for farm B. Individual cow daily milk yields from parlor meters were averaged across the $7 \mathrm{~d}$ preceding the test day. To estimate genetic potential for milk fat production, EBV of fat percent was calculated using each cow's sire and maternal grandsire milk fat percent PTA. Pedigree information was obtained from herd management software, PTA values were obtained from the Council on Dairy Cattle Breeding database (August 2018), and
EBV values were calculated as Sire PTA + 1/2 maternal grandsire PTA.

\section{Rumination Data Compiling and Filtering}

Rumination and other behaviors were recorded continuously by rumination sensors in the $7 \mathrm{~d}$ preceding each of the 8 test days. Data were reported by SCR as time spent ruminating and active in 2 -h intervals and by $\mathrm{CM}$ as time spent ruminating, eating, inactive, active, and highly active in 1-h intervals. For each 7-d observation period, rumination was summed within day for each cow, then averaged across days to obtain RT. Days with missing data or total RT $<200 \mathrm{~min}$ were removed due to suspected illness or technology malfunction. In CM data, very low rumination $(<100$ $\min / \mathrm{d}$ ) with very high time spent eating (700 to 800 $\mathrm{min} / \mathrm{d}$ ), and vice versa, was observed in some cows. This may be due to the sensor detecting rumination as eating or vice versa, and thus days with a ratio of rumination to eating time $<0.5$ or $>10$ were removed. This procedure removed $<30$ cows per farm. Lastly, if less than 2 complete days of rumination data were available, the cow was removed from that test period.

\section{Statistical Analysis}

Summary statistics for milk production and rumination at each test day were calculated within farm using JMP Pro v 13 (SAS Institute, Cary, NC). To assess how rumination varies from day to day, within-cow variation in RT was calculated as standard deviation (SD) of the $7 \mathrm{~d}$ of RT observation within each test period.

Relationships between RT, variability (SD) of RT, and production of milk and components were analyzed within each farm using linear mixed models with the MIXED procedure in SAS v 9.4 (SAS Institute, Cary, NC). Relationships between predictor variables were assessed for potential collinearity before modeling using simple linear regression in JMP Pro v. 13, using variance inflation factor with a cutoff of 4 . All models included a repeated effect of test day with Cow as the subject. Variance components and autoregressive covariance structures were selected based on model convergence and Bayesian information criterion. Degrees of freedom for fixed effects were estimated using the KenwardRoger method. In each model, all potential interactions were tested and interactions $P<0.05$ that decreased model Bayesian information criterion were included. Data points with Studentized residuals outside of \pm 3.5 were considered outliers and removed from analysis. Significance of fixed effects was declared at $P<0.01$ and for interactions at $0.01<P<0.05$. The percentage 
of total variation in the output variable explained by model terms was calculated as the coefficient of determination $\left(\mathbf{R}^{2}\right)$ between actual and predicted values from models with and without the term, as described by Byskov et al. (2015).

The first set of models assessing the relationship of rumination and milk fat were

$$
Y=\mu+F_{i}+C+D+M+P_{k}+E+O+R+e_{i j k l},
$$

where $Y$ is milk fat concentration, $\mu$ is the overall mean, $C$ is the random effect of Cow, $D$ is the random effect of test date (expressed numerically and fit as class levels due to uneven spacing between dates), $M$ is the fixed effect of milk yield, $P$ is the fixed effect of parity $(k=1$, 2 , or $\geq 3), E$ is the fixed effect of EBV for fat percent, $O$ is the fixed effect of milk protein percent, $R$ is the fixed effect of RT or RTSD, and $e_{i j k l}$ is residual error. The third model, which assessed the relationship between $\mathrm{RT}$ and cow and production variables, was identical to the first 2 models, but had RT as the output variable, included the fixed effect of milk fat percent, and did not include the fixed effect of EBV for fat percent.

\section{RESULTS AND DISCUSSION}

\section{Production and Rumination}

The 2 herds were similar in milk production and both maintained an average milk yield between 34 and 39 $\mathrm{kg} / \mathrm{d}$ throughout the year (Table 1 ). The herds differed notably in fat concentration; farm A experienced biohydrogenation (BH)-induced milk fat depression (MFD) at their second test day, but milk fat had recovered to $3.7 \%$ by the third test day. Comparatively, farm B had greater and more stable milk fat throughout the year, with greater herd average milk fat concentration than farm A at all tests, and higher milk fat yield at all but their February test.

Average RT was similar between the 2 herds (within 10-15 min) and ranged from 520 to $570 \mathrm{~min} / \mathrm{d}$ throughout the experiment (Table 2). This was expected as the herds were at a similar production level and were both consuming corn silage-based diets. However, RT was less variable in farm B, which used the SCR system, compared with farm A, which used the CM system. The SD of herd average RT at a single test ranged from 75 to $80 \mathrm{~min}$ in farm A, compared with 42 to 55 min in farm B. Andreen et al. (2019) also observed higher SD of rumination in $3 \mathrm{CM}$ compared with $2 \mathrm{SCR}$ farms, but larger experiments and direct comparisons of technologies on the same farm are needed to statistically compare systems. It is expected that recording of rumination differs between SCR and CM based on the systems' different sensor locations and platform specific algorithms. Based on the current data, it is not possible to discern precisely how much variation in RT was attributable to technology error between systems.

\section{Variation in Rumination Time}

Variability in commercial rumination data was quantified to enable better interpretation of changes in RT and its possible association with changes in milk fat production. If rumination reported by rumination sensing systems is highly variable, smaller increases in RT indicative of altered rumen fermentation may be obscured by this variation. In the current data set, daily RT within cows varied notably within the $7 \mathrm{~d}$ observation periods; means within-cow SD of rumination in farms A and B were 41 and 48 min, respectively. This demonstrates that while variability in sensor-reported RT across cows was greater in farm A, variability of RT within cows was fairly similar between the 2 farms. The majority of cows had a SD of rumination greater than $20 \mathrm{~min}$, with most falling between 30 and $60 \mathrm{~min}$ (Figure 1). It is also noteworthy that a considerable number of cows had a SD of RT above $60 \mathrm{~min}$. This may be due to inherent cow variation (e.g., some cows ruminate more variably than others) or due to interactions between the animal and sensor. In validations of the SCR system by Schirmann et al. (2009) and Ambriz-Vilichis et al. (2015), the mean difference between the observer and the sensor-reported RT was -0.45 and $-1.0 \mathrm{~min}$ per 2 -h interval, respectively, with a $95 \%$ confidence interval of -14.7 to 13.8 and -27 to $25 \mathrm{~min} / 2 \mathrm{~h}$ interval. Based on these mean differences, assuming a -0.25 to -0.5 min difference for all hours of the day, variation in reported RT that is attributable to technology is estimated as \pm 6 to $12 \mathrm{~min} / \mathrm{d}$ for cows when the sensor is functioning well. However, it is unknown whether the difference in minutes of RT between observation methods varies from day to day within individual cows or sensors (i.e., whether a cow's rumination is consistently under or overestimated). However, both validations concluded that for most cows, the SCR system reported rumination in close agreement with visual observation. In the CM system, day-to-day variability of reported RT is unclear, as mean differences of observer vs sensor-reported RT are not reported in published validations. Nonetheless, based on these estimates, it can be concluded that technology likely explains a relatively small portion of the variation in RT within and between cows.

Beyond the influence of technology, rumination is expected to be affected by many factors including diet 
Table 1. Average production and rumination time for 2 study farms (farms A and B) at each test day

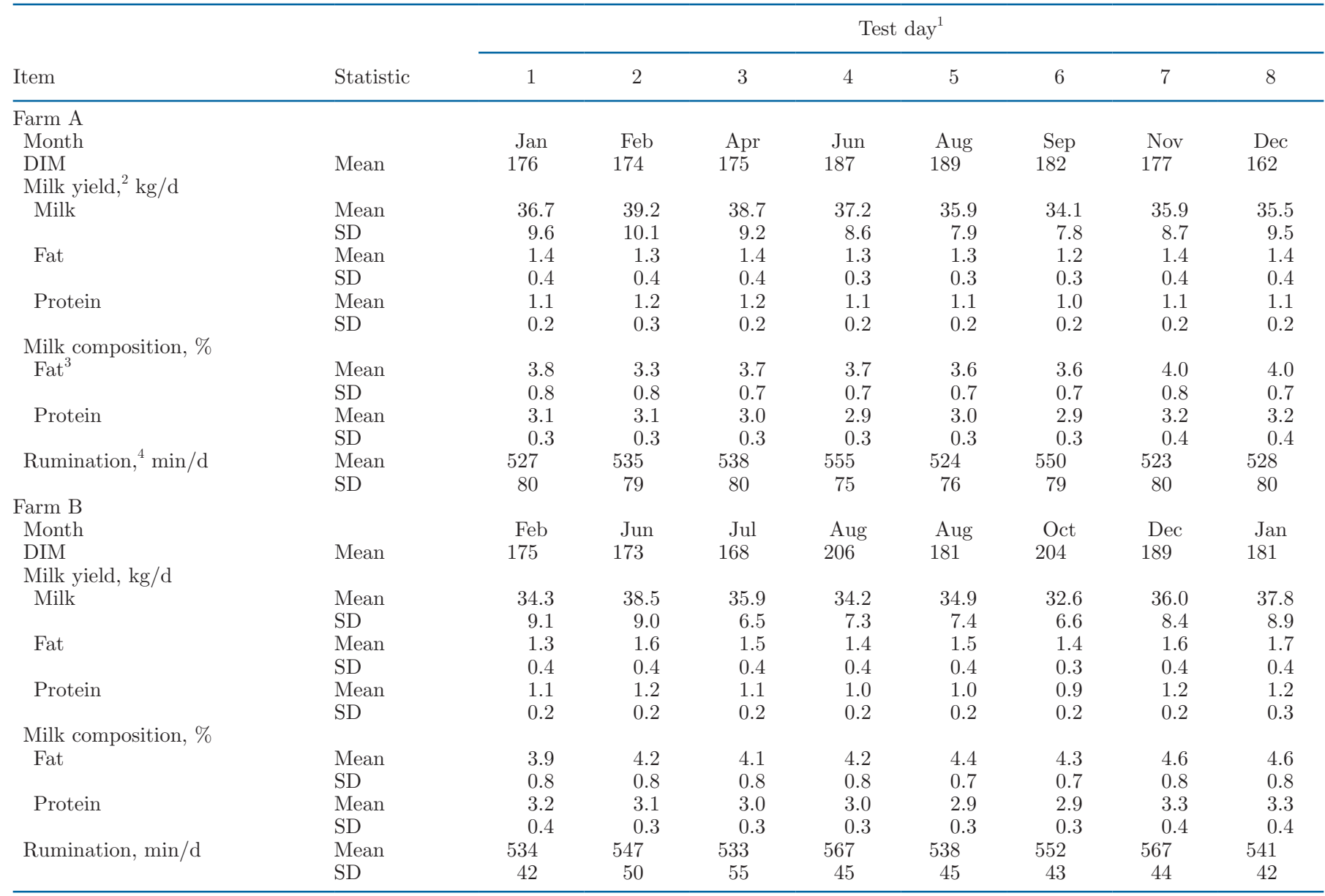

${ }^{1}$ Data were collected at 8 DHIA test days between January 2018 and January 2019 from a total of 1,823 lactating Holstein cows on 2 commercial dairy farms.

${ }^{2}$ Milk yield was calculated as the average daily yield in the $7 \mathrm{~d}$ preceding the DHIA test.

${ }^{3}$ Individual cow tests with milk fat $\geq 7 \%$ were excluded.

${ }^{4}$ Rumination time was calculated as mean rumination $(\mathrm{min} / \mathrm{d})$ in a 7-d period preceding the DHIA test. Rumination was measured on farm A with the CowManager SensoOr ear tag system (Agis Automatisering BV, Harmelen, the Netherlands) and on farm B with the SCR neck-collar system (SCR Engineers, Netanya, Israel).

composition, milk production, and cow health, and thus can be expected to vary from day to day (Beauchemin, 2018). Variability of daily RT across cows has been examined by other researchers using various methods of measuring rumination, but within-cow variation has been less explored (Dado and Allen, 1994; Byskov et al., 2015). In this data set it was not possible to differentiate healthy cows from those with altered rumen fermentation or other problems, and thus these values may not perfectly reflect variation in RT of healthy animals vs. those with MFD conditions. However, only a small number of cows would be expected to be sick or in estrus during each observation period.

Rumination sensing systems identify reproduction and health management alerts by detecting deviations from baseline RT that occur during estrus or illness; however, these deviations are typically substantial and sudden, and therefore easier to detect. For example, Reith and Hoy (2012) assessed changes in daily RT within $3 \mathrm{~d}$ relative to estrus in 4 farms with the SCR system and observed that cows in estrus decreased RT by 60 to 94 min compared with mean RT of their 2 previous nonestrus days. While rumination sensing systems are certainly capable of detecting and interpreting sudden changes to daily RT, potential changes in RT due to onset of MFD may be too gradual or subtle to reliably detect with the existing systems. Additionally, commercial sensors rely on changes in multiple variables such as physical activity, which has been demonstrated to increase in most cows during estrus, to detect estrus, 

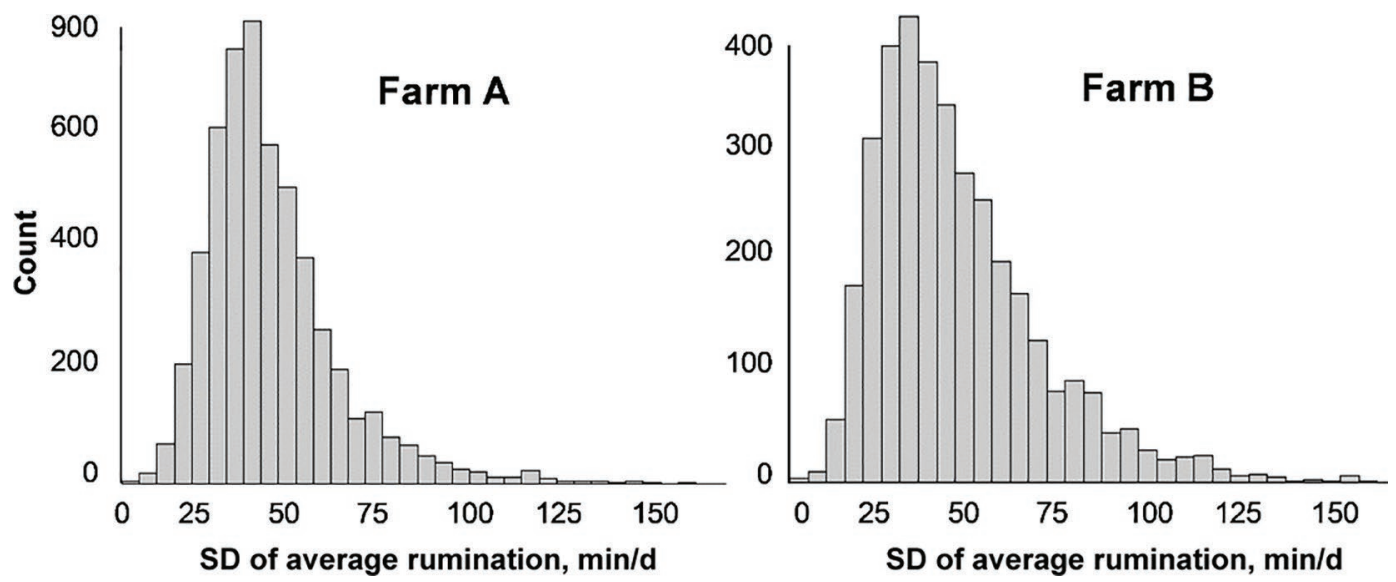

Figure 1. Within-cow variation in daily rumination time of lactating Holstein cows within farms A and B. A total of 8,586 cow-weeks of data from 2 commercial dairy farms over 1 yr were used. The standard deviation of rumination time was calculated for each cow over a 7-d period preceding each DHIA test. Mean SD was $41 \pm 20$ and $48 \pm 23$ min (mean \pm SD) for farm A and farm B, respectively. Rumination was measured on farm A with the CowManager SensoOr ear tag system (Agis Automatisering BV, Harmelen, the Netherlands) and on farm B with the SCR neck-collar system (SCR Engineers, Netanya, Israel).

whereas activity may be less useful in detection of nutrition issues (Reith and Hoy, 2012).

\section{Relationships Between Rumination Time and Cow and Production Variables}

Before mixed modeling, the bivariate relationships between study variables (RT, DIM, milk yield, milk fat percent, and milk protein percent) were explored (Figure 2). Milk fat concentration was inversely related to milk yield and positively related to DIM in both farms, as expected, but there was considerable vari- ability around the trendline. Milk fat concentration was most highly related to milk protein concentration $\left(\mathrm{R}^{2}=\right.$ $14 \%$ for farm A and $17 \%$ for farm B). The production variable most related to $R T$ was milk yield with an $R^{2}$ of $7.6 \%$ in farm A and $6.0 \%$ in farm B. Positive associations between milk yield and RT have been observed by other researchers and are probably driven by increased DMI, which increases rumen fill and the quantity of large particles that require chewing (Soriani et al., 2012; Stone et al., 2017). Milk protein and fat concentration were significantly related to $\mathrm{RT}(P<0.01$ for both farms), but trendlines had very small slope values

Table 2. Multivariant mixed models of milk fat concentration used to determine the relationships between milk fat and rumination time (min/d) within each farm

\begin{tabular}{|c|c|c|c|c|c|c|}
\hline Item & \multicolumn{3}{|c|}{ Farm A } & \multicolumn{3}{|c|}{ Farm B } \\
\hline Intercept & 1.52 & 0.35 & $<0.001$ & 2.31 & 0.19 & $<0.001$ \\
\hline Milk yield ${ }^{2} \mathrm{~kg} / \mathrm{d}$ & 0.05 & 0.009 & 0.006 & 0.003 & 0.005 & 0.493 \\
\hline Protein, \% & 0.98 & 0.10 & $<0.001$ & 0.64 & 0.04 & $<0.001$ \\
\hline Fat $\%$, EBV & 1.10 & 0.15 & $<0.001$ & 1.53 & 0.19 & $<0.001$ \\
\hline 2 & 0.06 & 0.10 & 0.548 & 0.13 & 0.14 & 0.352 \\
\hline$\geq 3$ & Referent & - & - & Referent & - & - \\
\hline Milk yield $\times$ Parity & & & $<0.001$ & & & 0.017 \\
\hline 1 & -0.02 & 0.004 & $<0.001$ & -0.01 & 0.005 & 0.032 \\
\hline 2 & -0.004 & 0.003 & 0.134 & -0.008 & 0.004 & 0.023 \\
\hline$\geq 3$ & Referent & - & - & Referent & - & - \\
\hline Milk yield $\times$ Protein $\%$ & -0.01 & 0.00 & $<0.001$ & & & \\
\hline
\end{tabular}

${ }^{1}$ Rumination time (RT) was calculated as the average daily rumination from the $7 \mathrm{~d}$ preceding a DHIA test. Rumination was measured on farm A with the CowManager SensoOr ear tag system (Agis Automatisering BV, Harmelen, the Netherlands) and on farm B with the SCR neck-collar system (SCR Engineers, Netanya, Israel).

${ }^{2}$ Milk yield was calculated as the average of the 7 daily yields preceding the DHIA test. 
(regression coefficient, $\beta=-9.7$ and -2.8 for farms $\mathrm{A}$ and $\mathrm{B}$, respectively; Figure 3).

\section{Mixed Models}

Milk Fat Concentration. Multivariate mixed models were used to determine the relationship between RT and milk fat percent while accounting for the random effects of cow and test date, as well as the fixed effects of milk protein percent, pedigree EBV of milk fat percent, and parity (Table 3). Both milk and DIM were evaluated in models for milk fat percent, and milk yield consistently performed better than DIM. In models of milk fat within each farm, rumination tended to be associated with lower milk fat concentration in farm A and was not related to milk fat in farm B. However, the coefficient of milk fat in farm A, while near-significant, was small. Based on the farm A model, a 60-min increase in RT would result in a decrease in milk fat of only 0.02 percentage units. This suggests a potential association, but not a strong, direct relationship that would enable prediction of milk fat from RT. Removal of the RT term decreased $\mathrm{R}^{2}$ of the farm $\mathrm{A}$ data set model by only $\sim 1 \%$, indicating the term contributed minimally to the variation explained by the model.

Milk yield was negatively associated with milk fat concentration with a larger effect of milk yield in primiparous compared with multiparous cows. Protein concentration was positively related to milk fat concentration, as was observed in the initial bivariate analysis, and interacted with milk yield in farm A. The relationship between milk fat and milk protein decreased as
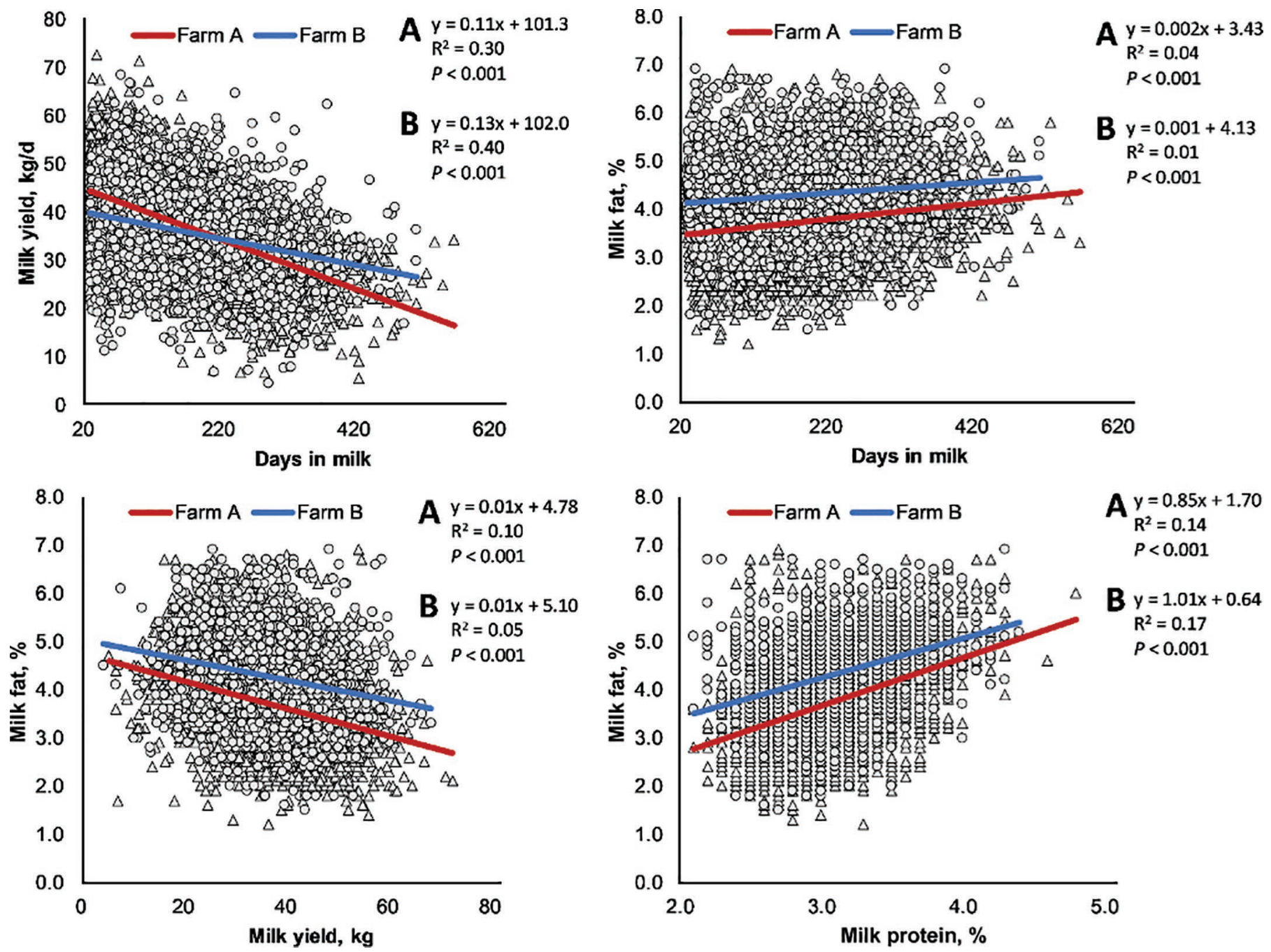

Figure 2. Bivariate relationships between key production variables within farm A (triangular markers) and farm B (circular markers). Data from a total of 8,586 DHIA test days from 2 commercial dairy farms were used. Milk yield was measured by integrated parlor milk meters and was calculated as the average over the $7 \mathrm{~d}$ preceding the DHIA test. All cows were Holsteins $\geq 30$ DIM, and individual cow test-days with milk fat percent $>7 \%$ were removed. 


\section{Farm A}
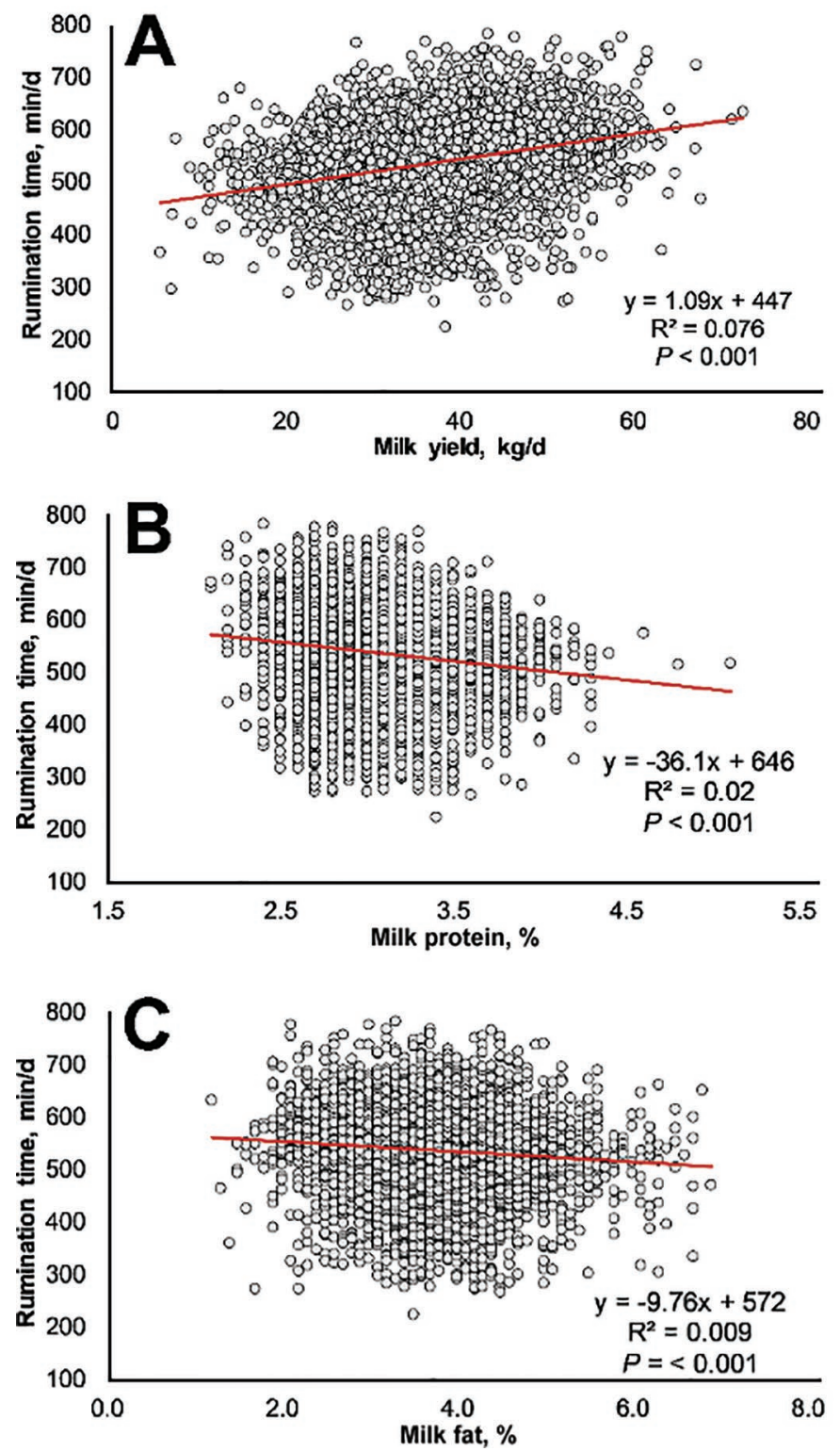

Farm B
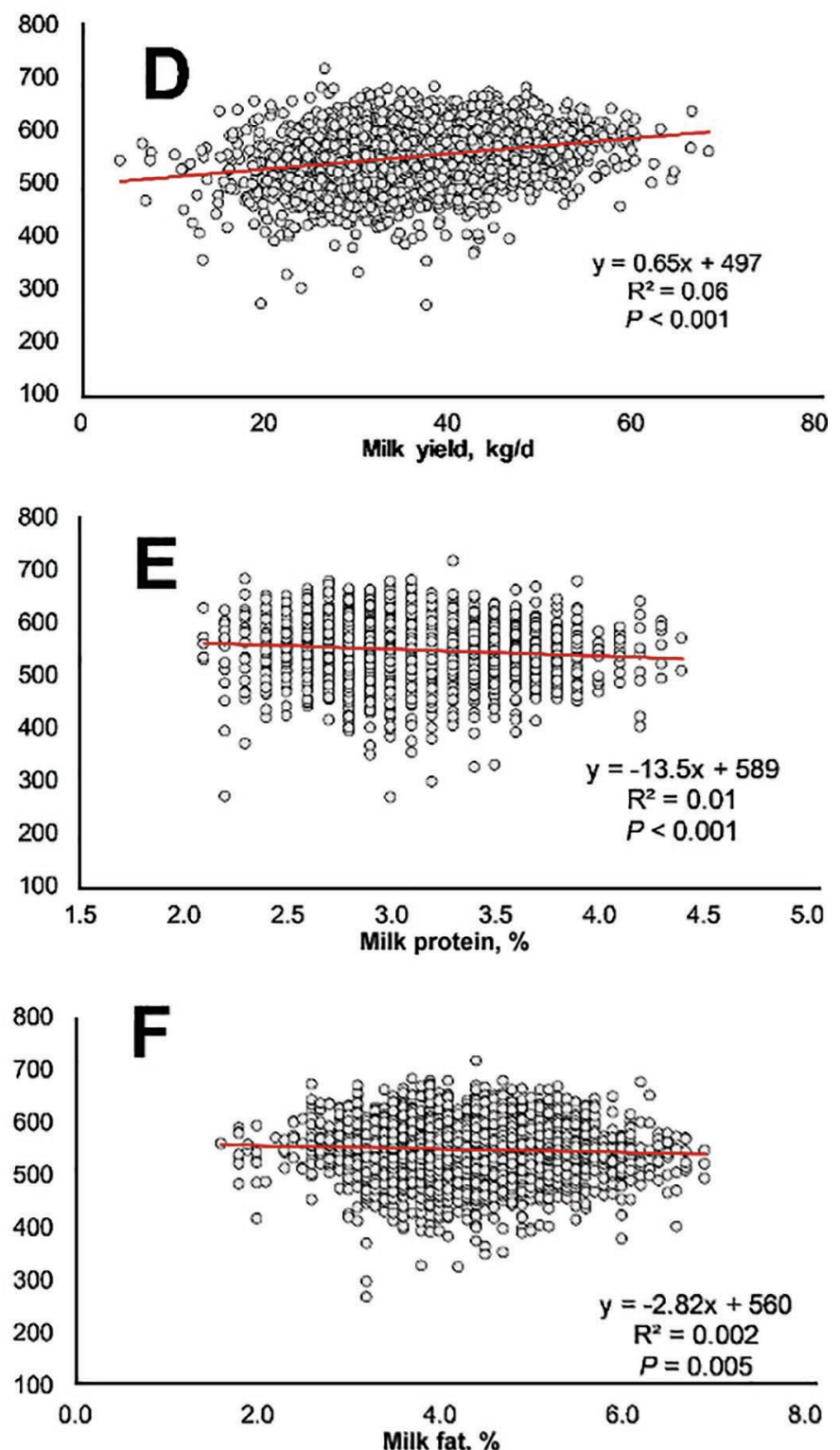

Figure 3. Bivariate relationships between rumination time and milk yield, milk protein, and fat concentration in farm A (panels A-C) and farm B (panels D-F). Data from a total of 8,586 DHIA test days from 2 commercial dairy farms were used. Milk yield was measured by integrated parlor milk meters and was calculated as the average of the $7 \mathrm{~d}$ preceding the DHIA test. All cows were Holsteins $\geq 30$ DIM, and individual cow test-days with milk fat percent $>7 \%$ were removed. Rumination time was calculated as the average daily rumination in the 7 -d period preceding a DHIA test. Rumination was measured on farm A with the CowManager SensoOr ear tag system (Agis Automatisering BV, Harmelen, the Netherlands) and on farm B with the SCR neck-collar system (SCR Engineers, Netanya, Israel).

milk yield increased, which could be due to the greater susceptibility of higher-producing cows to BH-induced MFD, affecting milk fat, but not milk protein concentration. Lower-producing cows without MFD would be expected to have a tighter relationship between milk fat and protein compared with higher-producing cows, whose milk fat may be more influenced by MFD.
Rumination Time. Mixed models were also used to determine association of RT with cow and production variables within each farm (Table 4). In the farm A data set, milk yield was positively associated with $\mathrm{RT}$, and the relationship was stronger in primiparous than multiparous cows. Milk yield also interacted with protein concentration in both farms, with a greater 
Table 3. Multivariant mixed models of rumination time $(\mathrm{min} / \mathrm{d})^{1}$ for determination of relationships between rumination time (min/d) and production variables within each farm

\begin{tabular}{|c|c|c|c|c|c|c|}
\hline Term & \multicolumn{3}{|c|}{ Farm A } & \multicolumn{3}{|c|}{ Farm B } \\
\hline Protein, \% & -19.0 & 3.16 & $<0.001$ & -16.7 & 7.63 & 0.029 \\
\hline Fat, $\%$ & -17.4 & 3.71 & $<0.001$ & 0.81 & 1.07 & 0.445 \\
\hline Parity & & & $<0.001$ & & & $\mathrm{NS}^{3}$ \\
\hline$\geq 3$ & Referent & - & - & & & \\
\hline Milk yield $\times$ Parity & & & 0.004 & & & \\
\hline 1 & -3.07 & 0.32 & $<0.001$ & & & \\
\hline 2 & -0.85 & 0.21 & $<0.001$ & & & \\
\hline$\geq 3$ & Referent & - & - & & & \\
\hline Milk yield $\times$ Protein $\%$ & 0.27 & 0.10 & 0.004 & 0.55 & 0.21 & 0.008 \\
\hline Milk yield $\times$ Fat $\%$ & 0.12 & 0.04 & 0.004 & & & \\
\hline
\end{tabular}

${ }^{1}$ Rumination time was calculated as the average daily rumination time from the $7 \mathrm{~d}$ preceding the DHIA test. Rumination was measured on farm A with the CowManager SensoOr ear tag system (Agis Automatisering BV, Harmelen, the Netherlands) and on farm B with the SCR neck-collar system (SCR Engineers, Netanya, Israel).

${ }^{2}$ Milk yield was calculated as the average of the 7 daily yields preceding the DHIA test.

${ }^{3}$ Term estimates not reported due to nonsignificance in model.

association between milk yield and RT in cows with lower milk protein. For farm A, milk fat was negatively related to RT and interacted with milk yield, but was not significant for farm B. Coefficients of the milk fat term in the farm A model, while significant, were relatively small. Based on this model, if milk fat decreased drastically from $3.5 \%$ to $2.5 \%$ (with all other variables held constant), a cow producing $36 \mathrm{~kg} / \mathrm{d}$ of milk would be predicted to increase RT by only $\sim 13 \mathrm{~min} / \mathrm{d}$.

The interaction of milk yield with milk fat concentration in the farm A data set indicates that the change in RT associated with milk fat decreased slightly as milk yield increased, which was unexpected. Higherproducing cows were expected to have a greater change in RT associated with milk fat because high-producing cows are more prone to BH-induced MFD and the possible associated increases in RT (Harvatine and Allen, 2006; Baldin et al., 2018). The nature of the observed interaction may be related to the lower ability of highproducing cows to increase their RT. Cows with greater milk yield have longer daily RT, and therefore may not be able to increase RT as much because they are al-

Table 4. Multivariant mixed models of milk fat percent for determination of the relationships between milk fat concentration and variability of rumination time within each farm

\begin{tabular}{|c|c|c|c|c|c|c|}
\hline \multirow[b]{2}{*}{ Term } & \multicolumn{3}{|c|}{ Farm A } & \multicolumn{3}{|c|}{ Farm B } \\
\hline & Estimate & $\mathrm{SE}$ & $P$-value & Estimate & $\mathrm{SE}$ & $P$-value \\
\hline $\mathrm{SD}$ of rumination time ${ }^{2}$ & 0.001 & 0.00 & 0.048 & 0.001 & 0.00 & 0.002 \\
\hline Fat \%, EBV & 1.09 & 0.15 & $<0.001$ & 1.53 & 0.19 & $<0.001$ \\
\hline Protein, \% & 0.99 & 0.10 & $<0.001$ & 0.65 & 0.04 & $<0.001$ \\
\hline 2 & 0.06 & 0.10 & 0.570 & 0.14 & 0.14 & 0.346 \\
\hline$\geq 3$ & Referent & - & - & Referent & - & - \\
\hline Milk yield $\times$ Parity & & & $<0.001$ & & & 0.019 \\
\hline 1 & -0.02 & 0.004 & $<0.001$ & -0.01 & 0.01 & 0.035 \\
\hline 2 & -0.004 & 0.003 & 0.159 & -0.01 & 0.004 & 0.024 \\
\hline$\geq 3$ & Referent & — & - & Referent & — & - \\
\hline Milk yield $\times$ Protein $\%$ & -0.01 & 0.002 & $<0.001$ & & & \\
\hline
\end{tabular}

${ }^{1}$ Milk yield was calculated as the average of the 7 daily yields preceding the DHIA test.

${ }^{2}$ Standard deviation of rumination time was calculated as the SD of all daily rumination time observations in the 7-d period preceding a DHIA test. Rumination was measured on farm A with the CowManager SensoOr ear tag system (Agis Automatisering BV, Harmelen, the Netherlands) and on farm B with the SCR neck-collar system (SCR Engineers, Netanya, Israel). 
ready close to their biological maximum for daily $\mathrm{RT}$ (Soriani et al., 2012; Stone et al., 2017).

Using similar models, the relationship between within-cow variability in daily $\mathrm{RT}$ (SD of rumination time) and milk fat was assessed (Table 4). This metric was analyzed because there is interest in how variation in RT within pens or groups, as well as across the entire herd, may be used as a metric to monitor nutrition and feeding management (e.g., SCR Engineers Ltd, 2016). It is plausible that greater variation in RT could indicate more erratic feeding and rumination behavior, which may negatively affect the rumen environment and stability of fermentation. Based on this, it was theorized that greater day-to-day variation in RT of individual cows may be negatively associated with milk fat production. Unexpectedly, SD of RT was positively associated with milk fat in farm $\mathrm{B}$ and tended to be positively associated in farm A $(P=0.014$ and 0.048 , respectively). However, the coefficient of SD of RT was small (regression coefficient, $\beta=0.001$ ) in all models and is difficult to interpret as the analysis is based on standard deviations. The positive relationship could be due to adaptability of individual cows; cows that alter their rumination to meet changing rumen buffering needs may have more stable fermentation and fat production than those who do not. It is also possible that greater SD of RT is related to lower precision of rumination recording, rather than actual greater variability of RT, which may differ between the 2 rumination sensing systems.

These multivariate mixed models were conducted within each farm alone for several reasons. The CM (farm A) and SCR (farm B) rumination sensing systems have both been validated by independent researchers; however, differences in recording of rumination were expected based on differing sensor locations (ear tag for CM vs. neck collar for SCR), mathematical algorithms, and other unknowns. Studies with lactating cows wearing both CM ear tags and SCR HR Tag collars by Dolecheck et al. (2015) and Mayo et al. (2019) indicated that recording of rumination does indeed differ between the 2 systems, further emphasizing the need for separate analyses. Additionally, when mixed models were run using data from both farms, highly significant farm by RT and farm by milk fat percent interactions in models of milk fat and RT were observed, indicating the need for separate analyses (data not shown).

A different relationship between RT and milk fat concentration was observed for farm A vs. farm B. While this could be attributable to many reasons, this difference may be partially related to the higher prevalence of altered rumen fermentation and BH-induced MFD in farm A. Based on our previously collected, unpublished data from these farms, it was theorized that a greater number of cows on farm A may have experienced BHinduced MFD or other fermentation-related issues during the year-long data collection period. In comparison, farm B had higher and more stable herd milk fat throughout the year, suggesting that fewer cows experienced fermentation issues. However, this cannot be conclusively stated based on the experimental design. The effect of farm was unavoidably confounded with rumination sensing system, as the focus of the project was investigation of the relationship between rumination and milk fat within cows. The difference in relationship between the 2 farms could also be related to diet, management differences, or other unknown factors.

While milk fat and RT were significantly or nearsignificantly related in most models, removing either term reduced the model $\mathrm{R}^{2}$ only minimally. In the farm A data set model of milk fat, where RT and milk fat were more strongly associated compared with farm B, removing the RT term reduced model $\mathrm{R}^{2}$ by only $1 \%$. This indicates the terms were not major contributors to their respective models, which is likely due in part to the very strong influence of the effect of Cow in both RT and milk fat models. In the farm A data set, when modeling milk fat concentration, removing the effect of Cow reduced model $\mathrm{R}^{2}$ from $66 \%$ to $27 \%$. The effect was even more pronounced in the farm A model of RT; removing the effects of Cow and Cow(Farm) in the combined data set decreased the $\mathrm{R}^{2}$ from 80 to $13 \%$. This is similar to Byskov et al. (2015), who found that $\mathrm{R}^{2}$ of models predicting RT that included diet information improved from $32 \%$ to $90 \%$ when the random effects of Cow(Trial) and trial were included. The strong effect of Cow on RT was not unexpected because, as previously discussed, cows typically maintain a consistent baseline level of daily rumination. The large contribution of the effect of cows supports the dogma that baseline rumination is specific to individual cows and is fairly stable across multiple test days.

\section{Integrative Discussion}

Relationships between rumination and milk fat content have not been well explored, particularly in the context of BH-induced MFD and other subclinical conditions. These present findings generally agree with a recent smaller study by Johnston and DeVries (2018). Using a data set of 132 cow-week observations from 5 studies in an automatic milking system, the authors analyzed the relationship between milk fat concentration and RT as reported by SCR collars. Daily RT in this study, averaged by week for each cow as in the present study, was associated quadratically with milk fat content, although the relationship was not strong. John- 
ston and DeVries (2018) proposed that the quadratic relationship they observed could be related to greater dilution of milk components in higher-rumination cows, as rumination is positively related to milk yield. This reasoning could also partially explain the results of the present study; however, if the relationship between milk fat and rumination was mediated primarily by dilution, the relationship would be anticipated to be similar between the farms. Nonetheless, neither MFD nor dilution can conclusively be stated, from these data, as the definitive mechanism behind the weak relationships observed between milk fat and RT.

Several limitations in this study should be noted. While previously collected data on the prevalence of $\mathrm{BH}$-induced MFD within these 2 farms at 1 test day was available, similar data for all cows was not available at any other test day. Therefore, it was not possible to identify specific cows or the proportion of the herd experiencing MFD or other fermentation issues at each test. It can be inferred from our previous, unpublished data that farm A likely had more fermentation issues throughout the year-long data collection period compared with farm B, but this cannot be decisively confirmed. Therefore, while this study assessed how rumination was related to milk fat across a large number of cows, the experimental design did not enable determination of how RT and milk fat were related in cows with vs. without altered rumen fermentation. Additionally, of the cows that did experience altered fermentation during data collection, it was not possible to identify the timing of onset or recovery of MFD or other conditions. Timing of onset may be important because RT may shift during onset of altered fermentation, but then stabilize after a period of time. Lastly, while correct positioning of sensors on cows was confirmed and data filtering techniques were used, some amount of unknown technology error is expected to be present in the current data set.

\section{CONCLUSIONS}

Daily RT reported by commercial rumination systems varies across and within cows, and is strongly influenced by individual cow variation. Greater daily RT was associated negatively with milk fat concentration on farm A, but not farm B. The reason for this difference is unclear, but may be related to a potentially greater prevalence of altered rumen fermentation in farm A. While daily RT was weakly related to milk fat concentration in data from 1 of 2 farms, the relationship does not appear to be strong enough to permit prediction or identification of cows with $\mathrm{BH}$-induced MFD based on commercial RT data alone. Research directly assessing changes in RT before, during, and after onset of altered rumen fermentation is necessary to understand whether data from commercial rumination systems could be used to predict or identify cows with altered rumen fermentation.

\section{ACKNOWLEDGMENTS}

The authors thank the dairy farms that participated in this research; without them this study would not have been possible. We also thank Lancaster DHIA (Manheim, PA) and Dairy One DHIA (Ithaca, NY) for their assistance with data and milk sample acquisition. The authors acknowledge I. Salfer for assistance with statistical modeling. Research was supported in part by the Agriculture and Food Research Initiative Competitive Grant no. 2016-68008-25025 from the USDA National Institute of Food and Agriculture (PI KJH) and Penn State University, including USDA National Institute of Food and Agriculture Federal Appropriations under project number PEN04539 and accession number 1000803. The authors have not stated any conflicts of interest.

\section{REFERENCES}

Allen, M. S. 1997. Relationship between fermentation acid production in the rumen and the requirement for physically effective fiber. J. Dairy Sci. 80:1447-1462. https://doi.org/10.3168/jds.S0022 -0302(97)76074-0.

Ambriz-Vilchis, V., N. S. Jessop, R. H. Fawcett, D. J. Shaw, and A. I. Macrae. 2015. Comparison of rumination activity measured using rumination collars against direct visual observations and analysis of video recordings of dairy cows in commercial farm environments. J. Dairy Sci. 98:1750-1758. https://doi.org/10.3168/jds .2014-8565.

Andreen, D. A., M. M. Haan, C. D. Dechow, and K. J. Harvatine. 2019. Determination of the relationships between rumination time, milk fat production, and milk fatty acid profile using real-time rumination data. J. Dairy Sci. 102(Suppl. 1):412. (Abstr.)

Baldin, M., G. I. Zanton, and K. J. Harvatine. 2018. Effect of 2-hydroxy-4-(methylthio)butanoate (HMTBa) on risk of biohydrogenation-induced milk fat depression. J. Dairy Sci. 101:376-385. https: //doi.org/10.3168/jds.2017-13446.

Beauchemin, K. A. 2018. Invited review: Current perspectives on eating and rumination activity in dairy cows. J. Dairy Sci. 101:47624784. https://doi.org/10.3168/jds.2017-13706.

Bikker, J. P., H. van Laar, P. Rump, J. Doorenbos, K. van Meurs, G. M. Griffioen, and J. Dijkstra. 2014. Technical note: Evaluation of an ear-attached movement sensor to record cow feeding behavior and activity. J. Dairy Sci. 97:2974-2979. https://doi.org/10.3168/ jds.2013-7560.

Borchers, M. R., Y. M. Chang, I. C. Tsai, B. A. Wadsworth, and J. M. Bewley. 2016. A validation of technologies monitoring dairy cow feeding, ruminating, and lying behaviors. J. Dairy Sci. 99:74587466. https://doi.org/10.3168/jds.2015-10843.

Byskov, M. V., E. Nadeau, B. E. O. Johansson, and P. Nørgaard. 2015. Variations in automatically recorded rumination time as explained by variations in intake of dietary fractions and milk production, and between-cow variation. J. Dairy Sci. 98:3926-3937. https:// doi.org/10.3168/jds.2014-8012. 
Dado, R. G., and M. S. Allen. 1994. Variation in and relationships among feeding, chewing, and drinking variables for lactating dairy cows. J. Dairy Sci. 77:132-144. https://doi.org/10.3168/jds.S0022 -0302(94)76936-8.

Dolecheck, K. A., W. J. Silvia, G. Heersche Jr., Y. M. Chang, D. L. Ray, A. E. Stone, B. A. Wadsworth, and J. M. Bewley. 2015. Behavioral and physiological changes around estrus events identified using multiple automated monitoring technologies. J. Dairy Sci. 98:8723-8731. https://doi.org/10.3168/jds.2015-9645.

Harvatine, K. J., and M. S. Allen. 2006. Effects of fatty acid supplements on milk yield and energy balance of lactating dairy cows J. Dairy Sci. 89:1081-1091. https://doi.org/10.3168/jds.S0022 -0302(06)72176-2.

Johnston, C., and T. J. DeVries. 2018. Short communication: Associations of feeding behavior and milk production in dairy cows. J. Dairy Sci. 101:3367-3373. https://doi.org/10.3168/jds.2017-13743.

Mayo, L. M., W. J. Silvia, D. L. Ray, B. W. Jones, A. E. Stone, I. C. Tsai, J. D. Clark, J. M. Bewley, and G. Heersche Jr.. 2019. Automated estrous detection using multiple commercial precision dairy monitoring technologies in synchronized dairy cows. J. Dairy Sci. 102:2645-2656. https://doi.org/10.3168/jds.2018-14738.

Reith, S., and S. Hoy. 2012. Relationship between daily rumination time and estrus of dairy cows. J. Dairy Sci. 95:6416-6420. https:/ /doi.org/10.3168/jds.2012-5316.

Schirmann, K., M. A. G. von Keyserlingk, D. M. Weary, D. M. Veira, and W. Heuwieser. 2009. Technical note: Validation of a system for monitoring rumination in dairy cows. J. Dairy Sci. 92:6052-6055. https://doi.org/10.3168/jds.2009-2361.

SCR Engineers Ltd. 2016. Rumination Monitoring White Paper. http: //www.scrdairy.com/images/PDF/broshures_24_6/Rum_12_A4 _Eng_May14_low.pdf.

Soriani, N., E. Trevisi, and L. Calamari. 2012. Relationships between rumination time, metabolic conditions, and health status in dairy cows during the transition period. J. Anim. Sci. 90:4544-4554. https://doi.org/10.2527/jas.2011-5064.

Stone, A. E., B. W. Jones, C. A. Becker, and J. M. Bewley. 2017. Influence of breed, milk yield, and temperature-humidity index on dairy cow lying time, neck activity, reticulorumen temperature, and rumination behavior. J. Dairy Sci. 100:2395-2403. https://doi .org/10.3168/jds.2016-11607.

\section{ORCIDS}

D. M. Andreen $\odot$ https://orcid.org/0000-0002-2848-126X

M. M. Haan ๑ https://orcid.org/0000-0002-8300-7528

C. D. Dechow 자 https://orcid.org/0000-0002-9012-2807

K. J. Harvatine $\odot$ https://orcid.org/0000-0001-6422-2647 